\title{
Childhood cancer and residential exposure to highways: a nationwide cohort study
}

\author{
Ben D. Spycher ${ }^{1}$ Martin Feller ${ }^{1,2} \cdot$ Martin Röösli $^{3,4} \cdot$ Roland A. Ammann $^{5}$ \\ Manuel Diezi $^{6} \cdot$ Matthias Egger $^{1} \cdot$ Claudia E. Kuehni $^{1}$
}

Received: 29 May 2015/ Accepted: 7 October 2015/Published online: 2 November 2015

(C) Springer Science+Business Media Dordrecht 2015

\begin{abstract}
Children living near highways are exposed to higher concentrations of traffic-related carcinogenic pollutants. Several studies reported an increased risk of childhood cancer associated with traffic exposure, but the published evidence is inconclusive. We investigated whether cancer risk is associated with proximity of residence to highways in a nation-wide cohort study including all children aged $<16$ years from Swiss national censuses in 1990 and 2000. Cancer incidence was investigated in time to event analyses (1990-2008) using Cox proportional hazards models and incidence density analyses (1985-2008) using Poisson regression. Adjustments were made for socio-economic factors, ionising background
\end{abstract}

The Swiss Paediatric Oncology Group and the Swiss National Cohort Study Group. Members of study groups in "Appendix".

Electronic supplementary material The online version of this article (doi:10.1007/s10654-015-0091-9) contains supplementary material, which is available to authorized users.

Ben D. Spycher

ben.spycher@ispm.unibe.ch

1 Institute of Social and Preventive Medicine (ISPM), University of Bern, Finkenhubelweg 11, 3012 Bern, Switzerland

2 Department of General Internal Medicine, Bern University Hospital, Bern, Switzerland

3 Swiss Tropical and Public Health Institute, Basel, Switzerland

4 University of Basel, Basel, Switzerland

5 Department of Paediatrics, University of Bern, Bern, Switzerland

6 Paediatric Hemato-Oncology Unit, Department of Paediatrics, University Hospital of Lausanne (CHUV), Lausanne, Switzerland radiation and electromagnetic fields. In time to event analysis based on 532 cases the adjusted hazard ratio for leukaemia comparing children living $<100 \mathrm{~m}$ from a highway with unexposed children $(\geq 500 \mathrm{~m})$ was 1.43 (95\% CI 0.79, 2.61). Results were similar in incidence density analysis including 1367 leukaemia cases (incidence rate ratio (IRR) 1.57 ; $95 \%$ CI 1.09, 2.25). Associations were similar for acute lymphoblastic leukaemia (IRR 1.64; $95 \%$ CI 1.10, 2.43) and stronger for leukaemia in children aged $<5$ years (IRR 1.92; $95 \%$ CI 1.22 , 3.04). Little evidence of association was found for other tumours. Our study suggests that young children living close to highways are at increased risk of developing leukaemia.

Keywords Leukaemia - Lymphoma - Traffic exhaust . Air pollution - Tumours of the central nervous system . Vehicle emissions

\section{Introduction}

Emissions from motor-vehicles are an important component of ambient air pollution and may contribute to health risks including cancer [1]. Various components of vehicle emissions are carcinogenic, including diesel exhaust [2], benzene, 1,3-butadiene, and benzo(a)pyrene [3]. Benzene and 1,3-butadiene are known to cause hematopoietic and lymphatic malignancies in occupationally exposed adults [3]. Concentrations of traffic related pollutants are considerably higher in the immediate vicinity of highways; decrease rapidly within the first $100 \mathrm{~m}$ and become indistinguishable from background levels by about $500 \mathrm{~m}[4,5]$. About $10 \%$ of the population in European Union member states live within $500 \mathrm{~m}$ from a highway [6]. 
Several studies have investigated whether traffic-related pollution is associated with an increased risk of childhood cancer [7-12]. The focus has been on leukaemia, and specifically acute lymphoblastic leukaemia (ALL), and tumours of the central nervous system (CNS). Exposure measures were typically based on residence near major roads (proximity measures) or on modelled or measured concentrations of individual pollutants. A recent review and meta-analysis of previous studies on traffic-related pollution and childhood leukaemia suggests increased risks with exposure at diagnosis or longest place of residence, but not with exposure at birth [13]. However, there was evidence of publication bias. Furthermore, the authors noted a trade-off between adequate control for confounding and avoiding the risk of selection bias: studies collecting detailed information on confounding factors were susceptible to bias due to self-selection of participants. Previous studies were case-control or ecologic studies; to our knowledge, no cohort study has been published.

We aimed to assess associations between residence near a highway and childhood cancers in a census-based nationwide cohort. Our focus was on hematopoietic and lymphatic malignancies (leukaemia, ALL, lymphoma) but we also considered CNS and other tumours. We considered exposure at a time point between birth and diagnosis (time of census) and at diagnosis, adjusted for a wide range of potential confounders, and investigated whether associations might differ between urban and rural areas and between calendar periods. We hypothesized that excess risk associated with proximity to highways, if present, should be greater in rural than in urban areas due to lower background concentrations and higher exposure contrasts, and greater before 2000 than after due to reductions in vehicle emissions.

\section{Methods}

\section{Study population}

The study population consisted of the Swiss resident population aged $<16$ years at the national censuses of 1990 and 2000. Data were obtained from the Swiss National Cohort (SNC), a research platform linking national censuses with national datasets on mortality, migration and birth [14]. This allows computing follow-up time from the time of the first census an individual was recorded in (entry into the cohort) to the end of 2008. Other data available from the SNC included geocoded place of residence and demographic and socio-economic data. We excluded children living in mobile or temporary dwellings and children whose residential coordinates were missing or could not be determined with a margin of error $<100 \mathrm{~m}$ (about $1.5 \%$ of all children). Geocodes were missing for persons who could not be assigned to a unique building, for instance, because they did not have a fixed residential address.

Incident cases of childhood cancer were identified through probabilistic record linkage with the Swiss Childhood Cancer Registry (SCCR). The SCCR is a population-based registry of high coverage. Recent estimates suggest that it includes $91 \%$ (about $95 \%$ since 1995) of all cancer cases diagnosed in Switzerland at $<16$ years of age since 1985 [15]. Eligible cases were those diagnosed during follow-up with a diagnosis classified according to the International Classification of Childhood Cancer, third edition (ICCC-3) (Supplementary Fig. S1) [16]. The SCCR collects address histories from diagnosis to birth allowing us to obtain residence at census time points. Record linkage between the SNC and the SCCR was based on sex, date of birth, maternal and paternal dates of birth, geocoded residence at census, municipality of residence at census and at birth, and nationality. Addresses were geocoded using a geo-referenced address list from the Swiss postal system (GeoPost) or manually using the online facility "map viewer" maintained by the Federal Office of Topography (swisstopo) at www.geo.admin.ch. Cases who were diagnosed before entry into the cohort were excluded (Supplementary Fig. S1).

\section{Outcomes}

Outcomes were all cancers (all ICCC-3 diagnostic groups), leukaemia (ICCC-3 main group I), ALL (Ia), lymphoma (II), CNS tumours (III) and all other cancers (All ICCC-3 groups except I-III).

\section{Exposure measurement}

Exposure to highways was measured as the distance from the place of residence at a given time point (census or diagnosis, see section on statistical analysis) to the nearest highway. For children living $<500 \mathrm{~m}$ from a highway, estimated traffic volume on the nearest highway segment was obtained for all vehicles, and for trucks. Digital maps of the highway network including data on the opening years of individual highway segments and on traffic volume were obtained from the Federal Office of Spatial Development. All roads referred to as 'Autobahn' (dualcarriage motorway) or 'Autostrasse' (high-speed road) were designated as highways. Traffic volume was available for each highway segment in both directions for various vehicle categories. Volumes for all categories in both directions were added to obtain total vehicle traffic volume. 


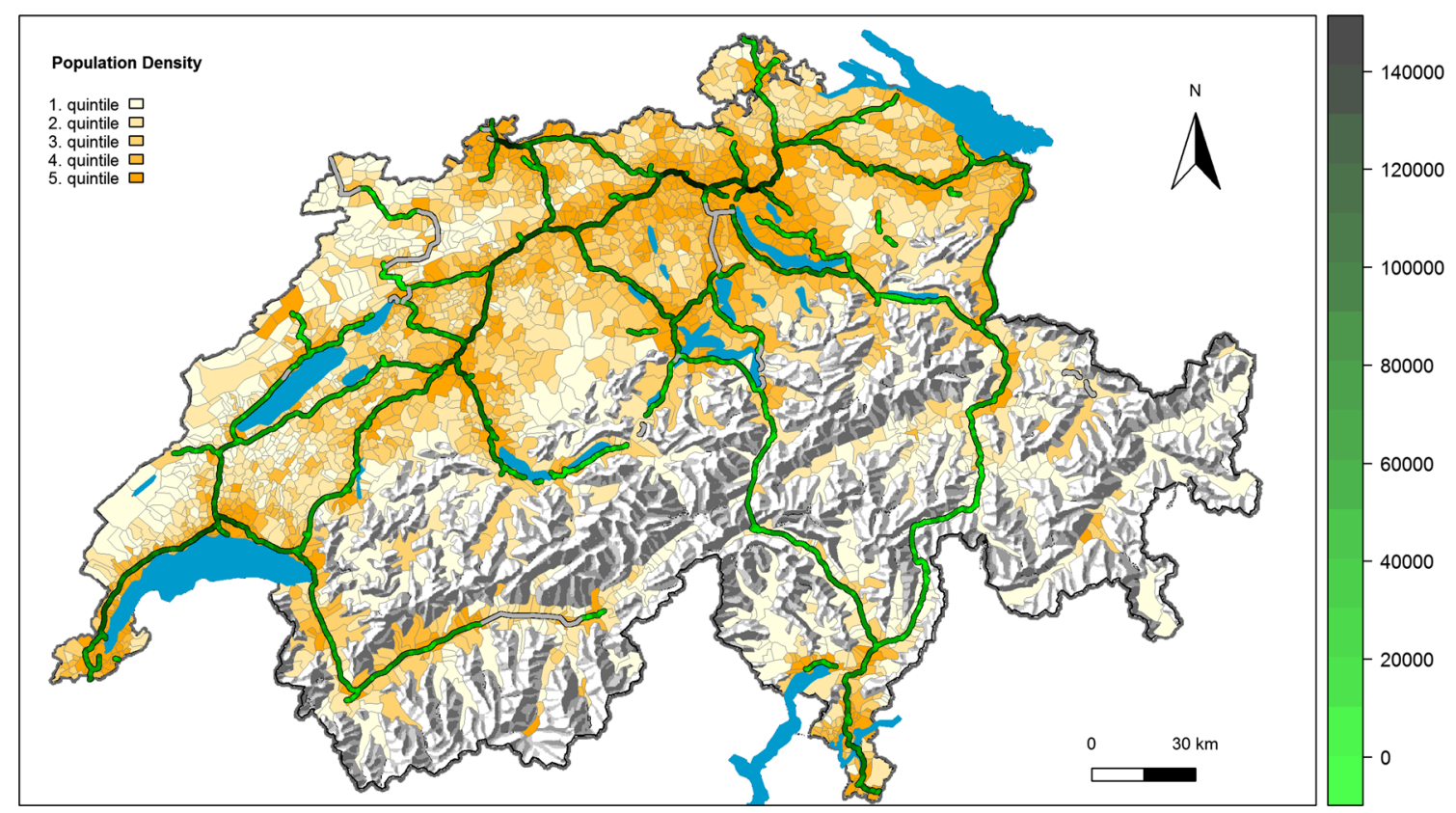

Fig. 1 Map showing traffic volume (vehicles per day) in 2005 on Swiss highway network and population density. Highway segments without information on traffic volume (mainly highways built after 2005) are shaded in grey

Volume of truck traffic included the categories trucks and semi-trailer trucks. We used the data for mean weekday road traffic volume in 2005 [17]. Figure 1 shows the Swiss highway network with traffic volumes.

\section{Potential confounding}

We considered confounding by following factors assessed for all children at census time points: degree of urbanisation (urban, peri-urban, rural), neighbourhood socio-economic position (Swiss-SEP index) [18], educational level of household head (compulsory, secondary, tertiary), crowding (number of persons per room), nationality (by continent for non-Swiss nationals), background ionising radiation (terrestrial gamma and cosmic rays) [19, 20], distance to nearest high voltage ( 380 or $220 \mathrm{kV}$ ) power lines, and strength of electromagnetic fields (EMF) from broadcast transmitters [21].

\section{Statistical analyses}

We analysed the data using two approaches: time to event analyses of the SNC with linked SCCR cases covering the period from the national census in 1990 to the end of 2008, and incidence density analyses using all SCCR cases diagnosed between 1985 and 2008 with person years at risk calculated from census data. In time to event analyses, exposure calculation was based on residence at the time of census as obtained from the SNC for all cohort members including linked cancer cases. In incidence density analyses, exposure was based on residence at diagnosis: for cases these were obtained from the SCCR while person year calculations were based on the residence of age and sex peers at the time of census as obtained from the SNC. In both approaches, we compared cancer risk across exposure categories $(<100,100-<250,250-<500$, and $\geq 500 \mathrm{~m}$ ) using the least exposed $(\geq 500 \mathrm{~m}$, referred to here as unexposed) as reference category.

In time to event analyses, we used Cox proportional hazards models with age as underlying time scale to calculate hazard ratios. Follow-up began at entry into cohort (census date: 4th December 1990 or 5th December 2000) and ended at diagnosis, the 16th birthday, emigration, death or administrative censoring (31st December 2008), whichever occurred first. Exposure could vary over time. Children living near a highway that opened after entry into the cohort were initially classified as unexposed and reclassified on 1st January of the first full year that the highway was in operation. Children registered in both censuses, but with differing places of residence were reclassified on the date of the 2000 census or on 5th December 1995 if at the 2000 census the child was reported to have lived at the new location for the past 5 years. Data on potential confounders were time-updated analogously. All models were adjusted for sex and birth year. In separate models we additionally included all other potential confounders. To explore potential effects of exposure misclassification due to mobility, we repeated analyses in the sub-cohort of children with stable place of residence before entry, i.e. children who had the same residence 5 years 
before entry or, if this data was missing (the main reason for this being that children were aged $<5$ years), who lived in the same municipality at birth.

Incidence density analyses included a considerably larger number of cases because it did not require record linkage between the SNC and SCCR and the study period could begin in 1985, a time by which the present level of coverage had largely been achieved. This approach has been described in detail elsewhere [22]. Incidence rates were calculated based on numbers of incident cases and persons years at risk (The calculation of person years is described in detail in the supplementary Text S1) and compared across exposure categories using Poisson regression models. All models were adjusted for sex, age at diagnosis and calendar year. We did not adjust for other potential confounders in these analyses. We also fitted models with distance as a continuous exposure variable allowing for a flexible functional form of the dependency of cancer risk on distance. For these analyses we only included children living $<1 \mathrm{~km}$ from a highway. Penalised cubic regression splines were used to model the dependency on distance with the degree of smoothing selected according to the Akaike Information Criterion [23].

In both approaches we investigated effect modification by time period (before and after 2000) and degree of urbanisation (urban vs. rural). In incidence density analyses for leukaemia we additionally stratified analyses by age of diagnosis $(0-4 ; 5-15$ years). We also investigated associations between cancer risk and traffic volume in children living $<500 \mathrm{~m}$ from a highway. Traffic volume was included as a linear term [in units of 10,000 (all vehicles) or 1000 (trucks) vehicles per day] and as quartiles and models were adjusted for distance to nearest highway. We also tested for interactions between traffic volume and distance to nearest highway. In these analyses, children living close to highways built after 2005 — and thus lacking information on traffic volumes-were excluded. All analyses were done using Stata version 12.1 (StataCorp, Texas, USA) except for the models with penalized regression splines which were fitted using the 'mgcv' package in the statistical software environment $\mathrm{R}$ version 3.1.3.

\section{Results}

\section{Characteristics of study population}

The time to event analyses included 2,096,402 children, after excluding those with a previous diagnosis of cancer or with uncertain place of residence (Supplementary Fig. S2). Of these 1783 developed a cancer during the follow-up period, including 532 children with leukaemia, 326 with lymphoma, and 420 with a CNS tumour. Mean follow-up time was 7.7 years. Follow-up time ended before the 16th birthday in $31.1 \%$ of the children. Reasons included administrative censoring (28.8\%), emigration $(2.1 \%)$, and death $(0.1 \%)$. Of the children entering the cohort at census 1990, $37 \%$ were still in follow-up at census 2000 (the main reason for prior censoring was reaching the 16th birthday). Of these, $96 \%$ could be linked with a record in the 2000 census. Of those linked $57 \%$ had relocated between the censuses. At entry into the cohort, 271,593 $(13.0 \%)$ children lived $<500 \mathrm{~m}$ and $28,162(1.3 \%)$ $<100 \mathrm{~m}$ from a highway. Compared to unexposed children, exposed children were more likely to live in urban areas, neighbourhoods of lower SEP, in households with crowding or low levels of education, and likely to be more exposed to background ionising radiation, power lines, or EMF from broadcast transmitters (Table 1).

The incidence density analyses included 4263 cancer cases (1367 leukaemias, 574 lymphomas, and 890 CNS tumours) and 30.4 million person-years. Compared to incidence density analyses, cases included in time to event analyses were older at diagnosis and thus less likely to have leukaemia and other cancers characterized by early onset (Supplementary Table S1).

\section{Childhood cancer and proximity to highways}

In time to event analyses, the hazard ratio (HR) comparing children living $<100 \mathrm{~m}$ from a highway with unexposed children was 1.47 (95 \% CI 0.81, 2.67) for leukaemia, 1.53 (95\% CI 0.79, 2.97) for ALL, 1.33 (95\% CI 0.66, 2.68) for CNS tumours, and 1.19 (95\% CI $0.83,1.70)$ for all childhood cancers (Table 2). Though based on few cases, HRs were higher for leukaemia diagnosed before 5 years of age: $2.02(95 \%$ CI $0.75,5.47)$ for leukaemia and 1.70 (0.54-5.35) for ALL. Adjusting for potential confounders had little effect on results (Table 2). Of the children included in time to event analyses, $66.5 \%$ had a stable place of residence before entry into the cohort. Of these, $57.1 \%$ lived at the same address 5 years earlier while the remaining-consisting mainly of children younger than 5 years at entry-lived in the same municipality at birth. Results were similar for children with stable place of residence, with somewhat increased effect estimates for leukaemia and ALL diagnosed before 5 years of age, for CNS tumours and the group of all cancers (Table 3). For leukaemia and ALL diagnosed before 5 years of age, effects estimates for the exposure category 100-250 m were also increased.

In incidence density analyses associations were slightly stronger for leukaemia and ALL, but weaker for CNS tumours compared to the time to event analysis. Incidence rate ratios (IRR) comparing children living $<100 \mathrm{~m}$ from a 
Table 1 Characteristics of study population at entry into the cohort by residential proximity to highways

\begin{tabular}{|c|c|c|c|c|c|}
\hline Characteristics & $<100 \mathrm{~m} \mathrm{~N}(\%)$ & $100-<250 \mathrm{~m} \mathrm{~N}(\%)$ & $250-<500 \mathrm{~m} \mathrm{~N}(\%)$ & $\geq 500 \mathrm{~m} \mathrm{~N}(\%)$ & $p$ value $^{\mathrm{a}}$ \\
\hline All children & $\mathrm{N}=28,162(100.0 \%)$ & $\mathrm{N}=80,207(100.0 \%)$ & $\mathrm{N}=163,224(100.0 \%)$ & $\mathrm{N}=1,824,809(100.0 \%)$ & \\
\hline \multicolumn{6}{|l|}{ Sex } \\
\hline Male & $14,422(51.2)$ & $41,275(51.5)$ & $84,123(51.5)$ & $934,900(51.2)$ & \multirow[t]{2}{*}{0.075} \\
\hline Female & $13,740(48.8)$ & $38,932(48.5)$ & $79,101(48.5)$ & $889,909(48.8)$ & \\
\hline \multicolumn{6}{|l|}{ Year of birth } \\
\hline 1974-1979 & $4544(16.1)$ & $13,384(16.7)$ & $28,263(17.3)$ & $331,293(18.2)$ & \multirow[t]{5}{*}{$<0.001$} \\
\hline 1980-1984 & $4689(16.7)$ & $13,799(17.2)$ & $28,107(17.2)$ & $337,104(18.5)$ & \\
\hline 1985-1989 & $5965(21.2)$ & $16,757(20.9)$ & $33,612(20.6)$ & $393,164(21.5)$ & \\
\hline 1990-1994 & $6131(21.8)$ & $17,265(21.5)$ & $34,719(21.3)$ & $372,083(20.4)$ & \\
\hline 1995-2000 & $6833(24.3)$ & $19,002(23.7)$ & $38,523(23.6)$ & $391,165(21.4)$ & \\
\hline \multicolumn{6}{|l|}{ Degree of urbanisation } \\
\hline Urban & $10,182(36.2)$ & $22,991(28.7)$ & $44,154(27.1)$ & $425,039(23.3)$ & \multirow[t]{3}{*}{$<0.001$} \\
\hline Peri-urban & $13,641(48.4)$ & $44,046(54.9)$ & $92,945(56.9)$ & $803,879(44.1)$ & \\
\hline Rural & 4,339 (15.4) & $13,170(16.4)$ & $26,125(16.0)$ & $595,891(32.7)$ & \\
\hline \multicolumn{6}{|l|}{ Swiss-SEP index } \\
\hline 1st quintile (low SEP) & $10,068(35.8)$ & $24,340(30.3)$ & $47,161(28.9)$ & $494,871(27.1)$ & \multirow[t]{6}{*}{$<0.001$} \\
\hline 2nd quintile & $5826(20.7)$ & $16,301(20.3)$ & $32,776(20.1)$ & $381,818(20.9)$ & \\
\hline 3rd quintile & 4944 (17.6) & $15,216(19.0)$ & $30,959(19.0)$ & $346,689(19.0)$ & \\
\hline 4th quintile & $3989(14.2)$ & $14,074(17.5)$ & $28,917(17.7)$ & $321,604(17.6)$ & \\
\hline 5th quintile (high SEP) & 3199 (11.4) & $9997(12.5)$ & $22,949(14.1)$ & $275,420(15.1)$ & \\
\hline Missing & $136(0.5)$ & $279(0.3)$ & $462(0.3)$ & $4407(0.2)$ & \\
\hline \multicolumn{6}{|c|}{ Education level of head of household } \\
\hline Compulsory or less & $6928(24.6)$ & $16,166(20.2)$ & $32,256(19.8)$ & $322,223(17.7)$ & \multirow[t]{4}{*}{$<0.001$} \\
\hline Secondary level & $13,448(47.8)$ & $39,945(49.8)$ & $80,478(49.3)$ & $907,664(49.7)$ & \\
\hline Tertiary level & $6422(22.8)$ & $20,984(26.2)$ & $44,217(27.1)$ & $537,309(29.4)$ & \\
\hline Not known & $1364(4.8)$ & $3112(3.9)$ & $6273(3.8)$ & $57,613(3.2)$ & \\
\hline \multicolumn{6}{|l|}{ Persons per room (tertiles) } \\
\hline$<0.82$ & $8381(29.8)$ & $26,235(32.7)$ & $54,328(33.3)$ & $662,620(36.3)$ & \multirow[t]{3}{*}{$<0.001$} \\
\hline $0.82-<1.08$ & $10,041(35.7)$ & $30,080(37.5)$ & $61,044(37.4)$ & $666,756(36.5)$ & \\
\hline$\geq 1.08$ & $9740(34.6)$ & $23,892(29.8)$ & $47,852(29.3)$ & $495,433(27.1)$ & \\
\hline \multicolumn{6}{|l|}{ Nationality (by continent) } \\
\hline Swiss & $18,338(65.1)$ & $57,068(71.2)$ & $117,655(72.1)$ & $1,422,164$ (77.9) & \multirow[t]{6}{*}{$<0.001$} \\
\hline Europe (non-Swiss) & $8420(29.9)$ & $20,230(25.2)$ & $39,870(24.4)$ & $353,563(19.4)$ & \\
\hline Africa & $346(1.2)$ & $747(0.9)$ & $1457(0.9)$ & $12,112(0.7)$ & \\
\hline America & $223(0.8)$ & $580(0.7)$ & $1159(0.7)$ & $11,770(0.6)$ & \\
\hline Asia/Oceania & $833(3.0)$ & $1566(2.0)$ & 3074 (1.9) & $25,044(1.4)$ & \\
\hline Missing & $2(0.0)$ & $16(0.0)$ & $9(0.0)$ & $156(0.0)$ & \\
\hline \multicolumn{6}{|c|}{ Background ionising radiation } \\
\hline$<100 \mathrm{nSv} / \mathrm{h}$ & $8916(31.7)$ & $26,282(32.8)$ & $56,149(34.4)$ & $715,103(39.2)$ & \multirow[t]{5}{*}{$<0.001$} \\
\hline $100-<150 \mathrm{nSv} / \mathrm{h}$ & $17,112(60.8)$ & $47,050(58.7)$ & $93,364(57.2)$ & $988,943(54.2)$ & \\
\hline $150-<200 \mathrm{nSv} / \mathrm{h}$ & $1588(5.6)$ & $5551(6.9)$ & $11,958(7.3)$ & $100,148(5.5)$ & \\
\hline$\geq 200 \mathrm{nSv} / \mathrm{h}$ & $535(1.9)$ & $1266(1.6)$ & $1577(1.0)$ & $18,117(1.0)$ & \\
\hline Missing & $11(0.0)$ & $58(0.1)$ & $176(0.1)$ & $2498(0.1)$ & \\
\hline \multicolumn{6}{|c|}{ Distance to high voltage power line } \\
\hline$<100 \mathrm{~m}$ & $428(1.5)$ & $1079(1.3)$ & $1515(0.9)$ & $13,033(0.7)$ & \multirow[t]{4}{*}{$<0.001$} \\
\hline $100-<250 \mathrm{~m}$ & $829(2.9)$ & $4002(5.0)$ & $5401(3.3)$ & $33,960(1.9)$ & \\
\hline $250-<500 \mathrm{~m}$ & $1625(5.8)$ & $5874(7.3)$ & $19,028(11.7)$ & $83,335(4.6)$ & \\
\hline$\geq 500 \mathrm{~m}$ & $25,269(89.7)$ & $69,194(86.3)$ & $137,104(84.0)$ & $1,691,983(92.7)$ & \\
\hline
\end{tabular}


Table 1 continued

\begin{tabular}{lllll}
\hline Characteristics & $<100 \mathrm{~m} \mathrm{~N}(\%)$ & $100-<250 \mathrm{~m} \mathrm{~N}(\%)$ & $250-<500 \mathrm{~m} \mathrm{~N}(\%)$ & $\geq 500 \mathrm{~m} \mathrm{~N}(\%)$ \\
\hline $\begin{array}{l}\text { Missing } \\
\text { EMF from broadcast transmitters }\end{array}$ & $11(0.0)$ & $58(0.1)$ & $176(0.1)$ & $2,498(0.1)$ \\
$<0.05 \mathrm{~V} / \mathrm{m}$ & $21,768(77.3)$ & $64,361(80.2)$ & $133,062(81.5)$ & $1,562,686(85.6)$ \\
$0.05-<0.2 \mathrm{~V} / \mathrm{m}$ & $4367(15.5)$ & $11,773(14.7)$ & $23,210(14.2)$ & $191,704(10.5)$ \\
$\geq 0.2 \mathrm{~V} / \mathrm{m}$ & $1911(6.8)$ & $3878(4.8)$ & $6617(4.1)$ & $67,109(3.7)$ \\
Missing & $116(0.4)$ & $195(0.2)$ & $335(0.2)$ & $3310(0.2)$ \\
\hline
\end{tabular}

$S E P$ socioeconomic position, EMF electromagnetic fields

${ }^{\text {a }}$ From Chi squared tests

${ }^{\mathrm{b}}$ Modelled field strength from radio- and TV-transmitters

highway with unexposed children were 1.57 (95\% CI $1.09,2.25)$ for leukaemia, 1.64 (95\% CI 1.10, 2.43) for ALL and 1.20 (95\% CI 0.72, 2.00) for CNS tumours (Table 4). Associations were strongest for leukaemia diagnosed before age 5 years: IRRs were 1.92 for leukaemia $(95 \%$ CI 1.22, 3.04) and 1.94 (95\% CI 1.18, 3.20) for ALL (Table 5). There was evidence of increased risk for any cancer (IRR 1.54; $95 \%$ CI 1.13, 2.11) before the age of 5 years, but no evidence of association at older ages (Table 5).

Results from time to event and incidence density analyses are summarised in Fig. 2 and supplementary Fig. S3 for diagnoses before the age of 16 and 5 years respectively. Overall, relative risks for the smallest distance category tended to be $>1$ for all outcomes except lymphoma, while they tended to be closer to 1 for the two intermediate distance categories. We found no evidence for effect modification by calendar period ( $p>0.2$ for all outcomes in both time to event and incidence density analyses, Supplementary Fig S4) or by degree of urbanisation $(p>0.2$, Supplementary Fig S5).

The fitted curves allowing for a flexible relationship between cancer risk and distance (included as a continuous exposure) within $1 \mathrm{~km}$ from highways show a marked increase in risk with proximity for leukaemia and ALL (Supplementary Fig. S6) particularly in children aged 0-4 years (Fig. 3). This rise follows an apparent dip in risk occurring around $350-500 \mathrm{~m}$. This dip is also apparent in categorical analyses (Tables 4,5) but appears to be limited to urban and peri-urban areas (Supplementary Fig. S5). The curves for other diagnostic groups and for the group of all cancers were comparatively flat (Supplementary Fig. S6).

\section{Childhood cancer and traffic volume on nearest highway}

Among children living $<500 \mathrm{~m}$ from a highway, the risk of any type of cancer increased with traffic volume: For every additional 10,000 vehicles/day the HR was 1.05 (95\% CI
$1.01,1.10)$ and the IRR 1.03 (95\% CI 1.00, 1.06) (Supplementary Tables S2 and S3). Highest estimates were found for lymphoma and the group of other malignant tumours, particularly in time to event analyses: HRs 1.14 (95\% CI 1.04, 1.25) and 1.07 (95\% CI 0.98, 1.16) respectively. No evidence of association with traffic volume was found for leukaemia and CNS tumours. A similar pattern was found for traffic volume of trucks. In incidence density analyses, we also investigated associations with traffic volume in corridors $<250$ and $<100 \mathrm{~m}$ around highways and found similar results (Supplementary Table S3). When traffic volume was included as a categorical term results suggested a U-shaped curve for the risk of lymphoma (Supplementary Table S4). We found no evidence of interaction between traffic volume and distance to nearest highway (Supplementary Fig. S7).

\section{Discussion}

\section{Main findings}

This nationwide cohort study in Switzerland showed an increased risk of leukaemia among children living in the immediate proximity $(<100 \mathrm{~m})$ of highways. The association was strongest for leukaemia in children aged below 5 years, for which a twofold higher risk was estimated. Results were similar for ALL. There was little evidence of an increase in risk in older children, or for lymphoma, CNS tumours or other cancers. Adjustment for a range of confounders, including indicators of socio-economic status did not materially affect results. Among children living $<500 \mathrm{~m}$ from a highway, an association with traffic volume was found for all cancers but not for leukaemia.

\section{Our study in the context of previous studies}

Our results are consistent with the findings of some but not all previous studies of childhood cancer and residence in 
Table 2 Association between childhood cancer and residential proximity to highways (time to event analyses)

\begin{tabular}{|c|c|c|c|c|c|}
\hline Outcome $^{\mathrm{a}}$ & Distance to highway (m) & Cases & $\mathrm{IR}^{\mathrm{b}}$ & $\operatorname{HR}(95 \% \mathrm{CI})^{\mathrm{c}}$ & Adj. HR $(95 \% \text { CI })^{\mathrm{d}}$ \\
\hline \multirow[t]{4}{*}{ Leukaemia } & $<100$ & 11 & 4.83 & $1.47(0.81,2.67)$ & $1.43(0.79,2.61)$ \\
\hline & $100-<250$ & 23 & 3.58 & $1.09(0.72,1.66)$ & $1.05(0.69,1.60)$ \\
\hline & $250-<500$ & 41 & 3.15 & $0.96(0.70,1.33)$ & $0.93(0.67,1.28)$ \\
\hline & $\geq 500$ & 457 & 3.26 & 1.00 & 1.00 \\
\hline \multirow[t]{4}{*}{ Leukaemia $<5$ years } & $<100$ & 4 & 25.98 & $2.02(0.75,5.47)$ & $2.17(0.80,5.89)$ \\
\hline & $100-<250$ & 8 & 19.14 & $1.50(0.73,3.07)$ & $1.50(0.73,3.08)$ \\
\hline & $250-<500$ & 9 & 10.67 & $0.85(0.43,1.66)$ & $0.84(0.42,1.66)$ \\
\hline & $\geq 500$ & 126 & 14.56 & 1.00 & 1.00 \\
\hline \multirow[t]{4}{*}{ ALL } & $<100$ & 9 & 3.95 & $1.53(0.79,2.97)$ & $1.50(0.77,2.92)$ \\
\hline & $100-<250$ & 17 & 2.65 & $1.03(0.63,1.67)$ & $0.99(0.61,1.62)$ \\
\hline & $250-<500$ & 31 & 2.38 & $0.93(0.64,1.34)$ & $0.90(0.62,1.30)$ \\
\hline & $\geq 500$ & 359 & 2.56 & 1.00 & 1.00 \\
\hline \multirow[t]{4}{*}{ ALL $<5$ years } & $<100$ & 3 & 19.49 & $1.70(0.54,5.35)$ & $1.81(0.57,5.72)$ \\
\hline & $100-<250$ & 7 & 16.75 & $1.48(0.69,3.17)$ & $1.47(0.68,3.16)$ \\
\hline & $250-<500$ & 8 & 9.49 & $0.85(0.41,1.73)$ & $0.83(0.40,1.72)$ \\
\hline & $\geq 500$ & 112 & 12.95 & 1.00 & 1.00 \\
\hline \multirow[t]{4}{*}{ Lymphoma } & $<100$ & 3 & 1.32 & $0.65(0.21,2.04)$ & $0.62(0.20,1.93)$ \\
\hline & $100-<250$ & 10 & 1.56 & $0.77(0.41,1.45)$ & $0.74(0.39,1.39)$ \\
\hline & $250-<500$ & 32 & 2.46 & $1.22(0.85,1.76)$ & $1.20(0.83,1.74)$ \\
\hline & $\geq 500$ & 281 & 2.01 & 1.00 & 1.00 \\
\hline \multirow[t]{4}{*}{ CNS tumours } & $<100$ & 8 & 3.51 & $1.33(0.66,2.68)$ & $1.38(0.68,2.79)$ \\
\hline & $100-<250$ & 13 & 2.02 & $0.77(0.44,1.34)$ & $0.79(0.45,1.37)$ \\
\hline & $250-<500$ & 35 & 2.69 & $1.02(0.72,1.45)$ & $1.06(0.74,1.50)$ \\
\hline & $\geq 500$ & 364 & 2.60 & 1.00 & 1.00 \\
\hline \multirow[t]{4}{*}{ Other malignant tumours } & $<100$ & 8 & 3.51 & $1.11(0.55,2.23)$ & $1.13(0.56,2.28)$ \\
\hline & $100-<250$ & 18 & 2.80 & $0.89(0.55,1.42)$ & $0.89(0.55,1.42)$ \\
\hline & $250-<500$ & 37 & 2.84 & $0.90(0.64,1.26)$ & $0.90(0.64,1.26)$ \\
\hline & $\geq 500$ & 442 & 3.16 & 1.00 & 1.00 \\
\hline \multirow[t]{4}{*}{ All cancers } & $<100$ & 30 & 13.16 & $1.19(0.83,1.70)$ & $1.18(0.82,1.70)$ \\
\hline & $100-<250$ & 64 & 9.96 & $0.90(0.70,1.15)$ & $0.89(0.69,1.14)$ \\
\hline & $250-<500$ & 145 & 11.14 & $1.01(0.85,1.19)$ & $1.00(0.84,1.19)$ \\
\hline & $\geq 500$ & 1544 & 11.02 & 1.00 & 1.00 \\
\hline
\end{tabular}

$A L L$ acute lymphoblastic leukaemia, $C N S$ central nervous system, $I R$ incidence rate, $H R$ hazard ratio, $C I$ confidence interval

${ }^{a}$ In children aged $<16$ years if not otherwise stated

${ }^{\mathrm{b}}$ Incidence rates are per 100,000 person years

${ }^{c}$ From Cox proportional hazard models adjusting for sex and birth year (reference category $\geq 500 \mathrm{~m}$ )

d Adjusting for sex, birth year, urbanisation, socio-economic position, educational level of household head, number of persons per room, nationality, background ionising radiation (terrestrial gamma and cosmic rays), distance to nearest power line, electro-magnetic fields from broadcast transmitters

the proximity to highly trafficked roads $[9,24-28]$. The largest of these studies, based on over 700 cases of ALL, found a doubling of the risk among children living within $500 \mathrm{~m}$ of high-speed highways and main roads compared to unexposed children [9]. Other studies using proximity measures found little support for an association with leukaemia risk [12, 29-32]. A nationwide Danish study with almost 1000 leukaemia cases using time-weighted cumulative exposure found no association with traffic density [29]. However, this study considered front-door roads only, and may have poorly captured pollution from other highly trafficked roads nearby. Consistent with our findings, previous studies looking at CNS tumours found no [29-31] or only weak evidence [28] of an increased risk associated with proximity to highly trafficked roads. To our knowledge, only three other studies have investigated 
Table 3 Association between childhood cancer and residential proximity to highways among children with stable place of residence ${ }^{\mathrm{a}}$ (time to event analyses)

\begin{tabular}{|c|c|c|c|c|c|}
\hline Outcome $^{b}$ & Distance to highway (m) & Cases & $\mathrm{IR}^{\mathrm{c}}$ & HR $(95 \% \mathrm{CI})^{\mathrm{d}}$ & Adj. HR $(95 \% \mathrm{CI})^{\mathrm{e}}$ \\
\hline \multirow[t]{4}{*}{ Leukaemia } & $<100$ & 8 & 5.31 & $1.51(0.75,3.05)$ & $1.45(0.72,2.94)$ \\
\hline & $100-<250$ & 20 & 4.72 & $1.35(0.86,2.12)$ & $1.28(0.81,2.02)$ \\
\hline & $250-<500$ & 26 & 3.02 & $0.87(0.58,1.29)$ & $0.83(0.56,1.25)$ \\
\hline & $\geq 500$ & 329 & 3.46 & 1.00 & 1.00 \\
\hline \multirow[t]{4}{*}{ Leukaemia $<5$ years } & $<100$ & 4 & 32.75 & $2.55(0.94,6.94)$ & $2.62(0.96,7.16)$ \\
\hline & $100-<250$ & 8 & 24.16 & $1.87(0.91,3.85)$ & $1.80(0.87,3.73)$ \\
\hline & $250-<500$ & 7 & 10.57 & $0.82(0.38,1.77)$ & $0.80(0.37,1.74)$ \\
\hline & $\geq 500$ & 103 & 14.92 & 1.00 & 1.00 \\
\hline \multirow[t]{4}{*}{ ALL } & $<100$ & 7 & 4.64 & $1.66(0.78,3.52)$ & $1.60(0.75,3.40)$ \\
\hline & $100-<250$ & 15 & 3.54 & $1.27(0.76,2.14)$ & $1.20(0.71,2.03)$ \\
\hline & $250-<500$ & 22 & 2.55 & $0.92(0.60,1.43)$ & $0.88(0.57,1.37)$ \\
\hline & $\geq 500$ & 262 & 2.76 & 1.00 & 1.00 \\
\hline \multirow[t]{4}{*}{ ALL $<5$ years } & $<100$ & 3 & 24.56 & $2.18(0.69,6.88)$ & $2.22(0.70,7.05)$ \\
\hline & $100-<250$ & 7 & 21.14 & $1.86(0.86,4.03)$ & $1.78(0.82,3.87)$ \\
\hline & $250-<500$ & 6 & 9.06 & $0.81(0.35,1.84)$ & $0.77(0.34,1.78)$ \\
\hline & $\geq 500$ & 90 & 13.03 & 1.00 & 1.00 \\
\hline \multirow[t]{4}{*}{ Lymphoma } & $<100$ & 3 & 1.99 & $0.96(0.31,3.00)$ & $0.91(0.29,2.85)$ \\
\hline & $100-<250$ & 7 & 1.65 & $0.79(0.37,1.69)$ & $0.77(0.36,1.64)$ \\
\hline & $250-<500$ & 23 & 2.67 & $1.28(0.83,1.97)$ & $1.28(0.83,1.98)$ \\
\hline & $\geq 500$ & 198 & 2.08 & 1.00 & 1.00 \\
\hline \multirow[t]{4}{*}{ CNS tumours } & $<100$ & 8 & 5.31 & $1.78(0.88,3.60)$ & $1.83(0.90,3.72)$ \\
\hline & $100-<250$ & 9 & 2.12 & $0.72(0.37,1.40)$ & $0.74(0.38,1.45)$ \\
\hline & $250-<500$ & 28 & 3.25 & $1.10(0.75,1.63)$ & $1.15(0.78,1.71)$ \\
\hline & $\geq 500$ & 277 & 2.92 & 1.00 & 1.00 \\
\hline \multirow[t]{4}{*}{ Other malignant tumours } & $<100$ & 7 & 4.64 & $1.35(0.64,2.86)$ & $1.36(0.64,2.87)$ \\
\hline & $100-<250$ & 14 & 3.30 & $0.96(0.56,1.64)$ & $0.95(0.56,1.63)$ \\
\hline & $250-<500$ & 29 & 3.36 & $0.98(0.67,1.44)$ & $0.98(0.66,1.43)$ \\
\hline & $\geq 500$ & 325 & 3.42 & 1.00 & 1.00 \\
\hline \multirow[t]{4}{*}{ All cancers } & $<100$ & 26 & 17.25 & $1.44(0.97,2.12)$ & $1.42(0.96,2.09)$ \\
\hline & $100-<250$ & 50 & 11.80 & $0.99(0.74,1.31)$ & $0.97(0.73,1.29)$ \\
\hline & $250-<500$ & 106 & 12.29 & $1.03(0.85,1.26)$ & $1.03(0.84,1.26)$ \\
\hline & $\geq 500$ & 1129 & 11.89 & 1.00 & 1.00 \\
\hline
\end{tabular}

$A L L$ acute lymphoblastic leukaemia, $C N S$ central nervous system, $I R$ incidence rate, $H R$ hazard ratio, $C I$ confidence interval

${ }^{a}$ Resident at the same address 5 years before entry into the cohort or resident in the same municipality at birth if younger than 5 years at entry

${ }^{\mathrm{b}}$ In children aged $<16$ years if not otherwise stated

${ }^{c}$ Incidence rates are per 100,000 person years

${ }^{\mathrm{d}}$ From Cox proportional hazard models adjusting for sex and birth year (reference category $\geq 500 \mathrm{~m}$ )

e Adjusting for sex, birth year, urbanisation, socio-economic position, educational level of household head, number of persons per room, nationality, background ionising radiation (terrestrial gamma and cosmic rays), distance to nearest power line, electro-magnetic fields from broadcast transmitters

lymphoma in relation to traffic exposure [11, 28, 29]. Consistent with our study, they found no evidence of an association.

Most studies investigating exposure to specific traffic related pollutants support an association with childhood leukaemia [9-12, 33-37]. An ecological study from Texas [35] and a recent case-control study from California [37] found increased risks of childhood leukaemia associated with elevated air concentrations of benzene. Both these studies found a stronger association for acute myeloid leukaemia (AML) than for ALL. Due to the small number of AML cases in our study, we did not perform separate analyses for AML. Another recent case-control study from California using modelled carbon monoxide as a proxy for 
Table 4 Association between childhood cancer and residential proximity to highways (incidence density analyses)

\begin{tabular}{|c|c|c|c|c|}
\hline Outcome & Distance to highway (m) & Cases & $\mathrm{IR}^{\mathrm{a}}$ & $\operatorname{IRR}(95 \% \mathrm{CI})^{\mathrm{b}}$ \\
\hline \multirow[t]{4}{*}{ Leukaemia } & $<100$ & 30 & 7.20 & $1.57(1.09,2.25)$ \\
\hline & $100-<250$ & 54 & 4.55 & $0.99(0.76,1.31)$ \\
\hline & $250-<500$ & 93 & 3.85 & $0.84(0.68,1.04)$ \\
\hline & $\geq 500$ & 1190 & 4.52 & 1.00 \\
\hline \multirow[t]{4}{*}{ ALL } & $<100$ & 25 & 6.00 & $1.64(1.10,2.43)$ \\
\hline & $100-<250$ & 43 & 3.62 & $0.99(0.73,1.35)$ \\
\hline & $250-<500$ & 75 & 3.11 & $0.85(0.67,1.08)$ \\
\hline & $\geq 500$ & 950 & 3.61 & 1.00 \\
\hline \multirow[t]{4}{*}{ Lymphoma } & $<100$ & 3 & 0.72 & $0.38(0.12,1.17)$ \\
\hline & $100-<250$ & 18 & 1.52 & $0.79(0.49,1.27)$ \\
\hline & $250-<500$ & 53 & 2.20 & $1.15(0.86,1.52)$ \\
\hline & $\geq 500$ & 500 & 1.90 & 1.00 \\
\hline \multirow[t]{4}{*}{ CNS tumours } & $<100$ & 15 & 3.60 & $1.20(0.72,2.00)$ \\
\hline & $100-<250$ & 26 & 2.19 & $0.73(0.50,1.09)$ \\
\hline & $250-<500$ & 83 & 3.44 & $1.16(0.92,1.45)$ \\
\hline & $\geq 500 \mathrm{~m}$ & 766 & 2.91 & 1.00 \\
\hline \multirow[t]{4}{*}{ Other malignant tumours } & $<100$ & 25 & 6.00 & $1.25(0.84,1.86)$ \\
\hline & $100-<250$ & 52 & 4.38 & $0.92(0.69,1.21)$ \\
\hline & $250-<500$ & 118 & 4.89 & $1.03(0.85,1.24)$ \\
\hline & $\geq 500$ & 1237 & 4.70 & 1.00 \\
\hline \multirow[t]{4}{*}{ All cancers } & $<100$ & 73 & 17.52 & $1.22(0.97,1.54)$ \\
\hline & $100-<250$ & 150 & 12.62 & $0.89(0.75,1.04)$ \\
\hline & $250-<500$ & 347 & 14.37 & $1.01(0.91,1.13)$ \\
\hline & $\geq 500$ & 3693 & 14.02 & 1.00 \\
\hline
\end{tabular}

$A L L$ acute lymphoblastic leukaemia, $C N S$ central nervous system, $I R$ incidence rate, IRR incidence rate ratio, $C I$ confidence interval

${ }^{a}$ Incidence rates are per 100,000 person years

b From Poisson regression models adjusting for sex, age and calendar year (reference category $\geq 500 \mathrm{~m}$ ) traffic related pollution showed a positive association for ALL but not for CNS tumours [11]. A Danish case-control study found an increased risk with higher levels of modelled nitrogen monoxide and benzene for Hodgkin's lymphoma, but not for leukaemia or CNS tumours [29]. No evidence of an association between traffic related pollutants and leukaemia was found in a recent Italian study [12].

Among studies that investigated leukaemia by age groups, those that found positive associations with traffic related pollution in all children-consistent with our study-found stronger associations in the age group $0-4$ years $[10,28]$. However, studies that found no evidence of association for leukaemia in all children found no such evidence in young children if these were investigated $[12,31]$.

\section{Limitations and strengths}

Our study used proximity to highways which is a crude measure of traffic related pollution and does not allow distinguishing between individual pollutants. Also, we did not account for proximity of residence to other roads or background levels of pollution. However, we adjusted for degree of urbanisation which should have partially corrected for higher background levels in urban areas. We did not have address histories for the entire cohort, which would have allowed us to investigate effects of timing and duration of exposure. However, we repeated analyses in a sub-cohort of children with stable residence for 5 years before entry into the cohort and found similar results. Precise geocodes were missing for a small minority of subjects $(1.5 \%)$. Results from time to event analyses are difficult to interpret in terms of exposure timing because time of census, when exposure was measured, can lie anywhere between birth and diagnosis. Information on traffic volume was only available for 2005 and is probably not accurate for early time points. However, highways that were highly trafficked have been so throughout the study period suggesting that the relative importance of highway segments was stable. In time to event analyses, linkage errors may have resulted 
Table 5 Association between childhood cancer and residential proximity to highways by age group (incidence density analyses)

\begin{tabular}{|c|c|c|c|c|c|c|c|}
\hline \multirow[t]{2}{*}{ Outcome } & \multirow[t]{2}{*}{ Distance to highway (m) } & \multicolumn{3}{|c|}{ Children aged $0-4$ years } & \multicolumn{3}{|c|}{ Children aged $5-15$ years } \\
\hline & & Cases & $\mathrm{IR}^{\mathrm{a}}$ & $\operatorname{IRR}(95 \% \mathrm{CI})^{\mathrm{b}}$ & Cases & $\mathrm{IR}^{\mathrm{a}}$ & $\operatorname{IRR}(95 \% \mathrm{CI})^{\mathrm{b}}$ \\
\hline \multirow[t]{4}{*}{ Leukaemia } & $<100$ & 19 & 14.76 & $1.92(1.22,3.04)$ & 11 & 3.82 & $1.19(0.65,2.16)$ \\
\hline & $100-<250$ & 35 & 9.63 & $1.26(0.89,1.77)$ & 19 & 2.30 & $0.72(0.45,1.13)$ \\
\hline & $250-<500$ & 40 & 5.44 & $0.71(0.51,0.97)$ & 53 & 3.16 & $0.99(0.74,1.31)$ \\
\hline & $\geq 500$ & 607 & 7.62 & 1.00 & 583 & 3.17 & 1.00 \\
\hline \multirow[t]{4}{*}{ ALL } & $<100$ & 16 & 12.43 & $1.94(1.18,3.20)$ & 9 & 3.12 & $1.28(0.66,2.47)$ \\
\hline & $100-<250$ & 28 & 7.71 & $1.21(0.82,1.76)$ & 15 & 1.82 & $0.75(0.45,1.25)$ \\
\hline & $250-<500$ & 33 & 4.49 & $0.70(0.49,0.99)$ & 42 & 2.50 & $1.03(0.75,1.41)$ \\
\hline & $\geq 500$ & 507 & 6.37 & 1.00 & 443 & 2.41 & 1.00 \\
\hline \multirow[t]{4}{*}{ All cancers } & $<100$ & 40 & 31.08 & $1.54(1.13,2.11)$ & 33 & 11.46 & $0.98(0.69,1.38)$ \\
\hline & $100-<250$ & 78 & 21.47 & $1.07(0.85,1.34)$ & 72 & 8.73 & $0.75(0.59,0.95)$ \\
\hline & $250-<500$ & 141 & 19.17 & $0.95(0.80,1.13)$ & 206 & 12.27 & $1.05(0.91,1.22)$ \\
\hline & $\geq 500$ & 1578 & 19.82 & 1.00 & 2115 & 11.51 & 1.00 \\
\hline
\end{tabular}

$A L L$ acute lymphoblastic leukaemia, $I R$ incidence rate, IRR incidence rate ratio, $C I$ confidence interval

${ }^{a}$ Incidence rates are per 100,000 person years

${ }^{\mathrm{b}}$ From Poisson regression models adjusting for sex, age and calendar year (reference category $\geq 500 \mathrm{~m}$ )

in some misclassification of exposures and outcomes. In incidence density analyses, calculations of person years at risk were approximate. However, results were consistent across these two analyses suggesting that neither of these issues caused important bias. While coverage of cancer registration was high, incomplete registration must have caused some misclassification of outcomes. Regional differences in registration are unlikely to exist at a scale smaller than the Swiss cantons. To investigate whether such differences may have affected our results, we repeated analyses for leukaemia adjusting for the Swiss cantons but results remained stable (data not shown).

Our study is unique in that it was based on individual data from the entire childhood population of a country. Since all data were obtained from routine sources of high coverage, the study is likely free of selection or response biases that may have affected previous case-control studies. For a given number of cases, our cohort design also provides greater statistical power than previous case-control designs which usually had 1-4 controls per case. It also allowed accounting for exposure changes over time due to new highway construction and mobility between the two censuses. The use of precise residential locations allowed capturing small-scale spatial variation of pollutant concentrations around highways, which are unlikely to have been captured in most ecological studies. Furthermore, in contrast to most previous studies, our study was able to account for a wide range of potentially important confounding factors.

\section{Interpretation of findings}

Our most consistent finding was that of a higher risk of leukaemia among children aged $<5$ years living within $100 \mathrm{~m}$ from a highway. Carcinogenic effects of traffic emissions are a plausible explanation for this association. Monitoring studies have shown that most of the decline from roadside to background concentrations of many traffic related pollutants occurs within the first $100 \mathrm{~m}$ from the highway. Particularly steep declines with distance from highway have been shown for carbon monoxide, nitrogen monoxide, ultrafine particles, black carbon and volatile organic compounds including benzene [4, 5, 38]. Our finding of an excess risk in children aged $<5$ years could indicate a time window of increased susceptibility to environmental exposures. For rural areas, where contamination from other roads is likely to be less important, our results were suggestive of a dose response in the risk of childhood leukaemia and ALL approaching background levels within $500 \mathrm{~m}$ from highways (Supplementary Fig. S5). However, statistical evidence for effect modification by degree of urbanisation was lacking.

Other findings of our study cast doubt on a causative role of pollution. Near highway concentrations of traffic pollutants are strongly affected by traffic volume [39]. While we did observe a positive association between traffic volume and risk of any cancer, we found little evidence that the risk of leukaemia was influenced by traffic volume among those living close to a highway. A possible explanation is the effect of sound barriers which are commonly 


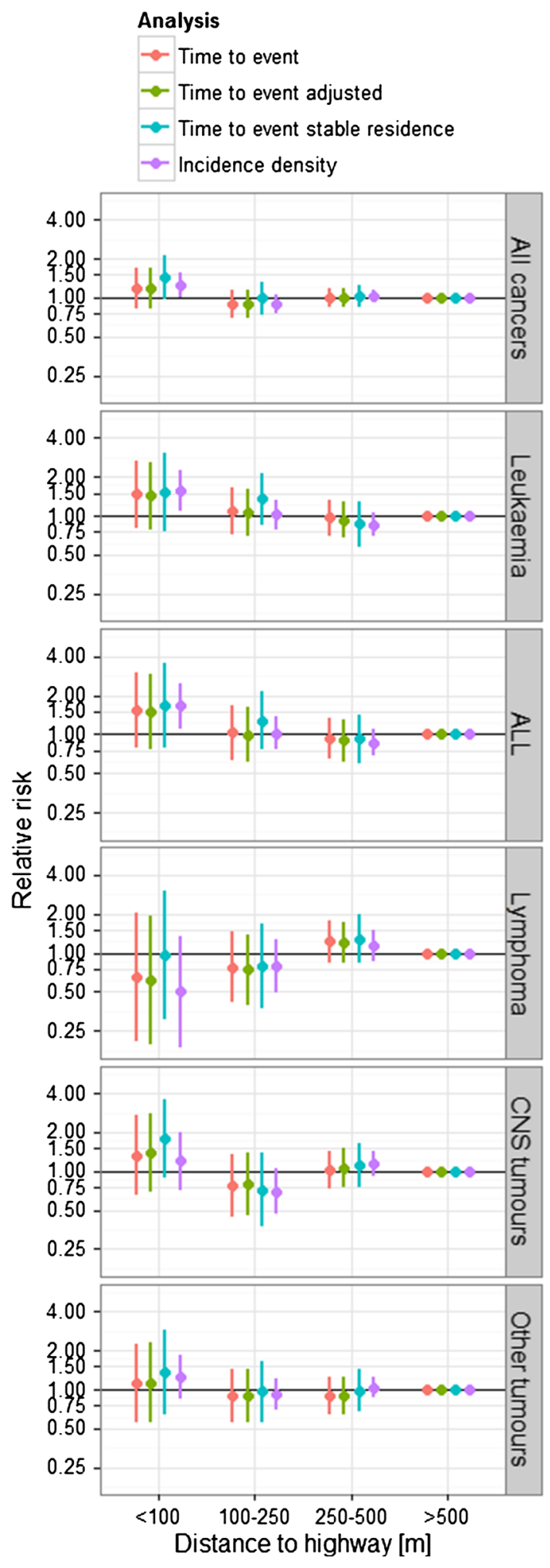

4Fig. 2 Associations between childhood cancer and distance of residence to nearest highway. Results from time to event analysis adjusting for sex and birth year; time to event analysis adjusting for sex, birth year, urbanisation, socio-economic position, educational level of household head, number of persons per room, nationality, background ionising radiation, distance to nearest power line, electromagnetic fields from broadcast transmitters; time to event analysis adjusting for sex and birth year in a subsample with stable place of residence 5 years preceding entry into cohort; incidence density analysis adjusting for sex, age and calendar year. Reference category is residence $>500 \mathrm{~m}$

used to shield residential areas from highways and have been shown to reduce downwind concentrations of traffic pollutants by lifting the plume and increasing vertical mixing [40]. Also, the observed increase in leukaemia risk may be due to elevated concentrations of individual pollutants of which total vehicle counts are a poor measure. Unfortunately we could not differentiate traffic flows by gasoline- and diesel-powered vehicles. Another unexpected finding was that the time period (before and after the year 2000) did not seem to affect the strength of association between leukaemia and proximity to highways, while traffic emissions have decreased dramatically in Switzerland since the early nineties [41, 42]. It is possible, however, that emission reductions affected background and roadside concentrations proportionately and that spatial gradients around highways and relative risks were little affected. Statistical power might also have been insufficient to detect an effect modification by calendar period.

Other factors that might be considered include traffic noise and socio-economic factors. Noise levels and traffic related air pollutants show similar associations with highway traffic [43] whereas noise levels may be more effectively offset by noise barriers. A possible causal path linking ambient noise with childhood leukaemia might be through immune responses. Ambient noise has been shown to affect immune response in mice [44]. Aberrant immune responses to infections have been hypothesized to cause childhood leukaemia [45]. Our findings are unlikely to be explained by socio-economic factors. Adjusting for a number of socio-economic indicators both at the neighbourhood and household level did not attenuate the estimated effects sizes for leukaemia.

In conclusion, this nationwide cohort study suggests that children living in the close proximity $(<100 \mathrm{~m})$ of highways are at increased risk of developing leukaemia. The association was strongest in children aged less than 5 years and in 
Fig. 3 Smoothed relative risks for leukaemia and ALL in children aged $0-4$ years by distance from nearest highway. Results from incidence density analysis with distance as a continuous exposure variable adjusting for sex, age and calendar year and restricting to children living $<1 \mathrm{~km}$ from a highway. Penalised cubic regression splines were used to model the association with distance and estimated risk. The estimated risk at $750 \mathrm{~m}$ was used as reference value (relative risk $=1)$. The shaded area represents point-wise $95 \%$ confidence intervals

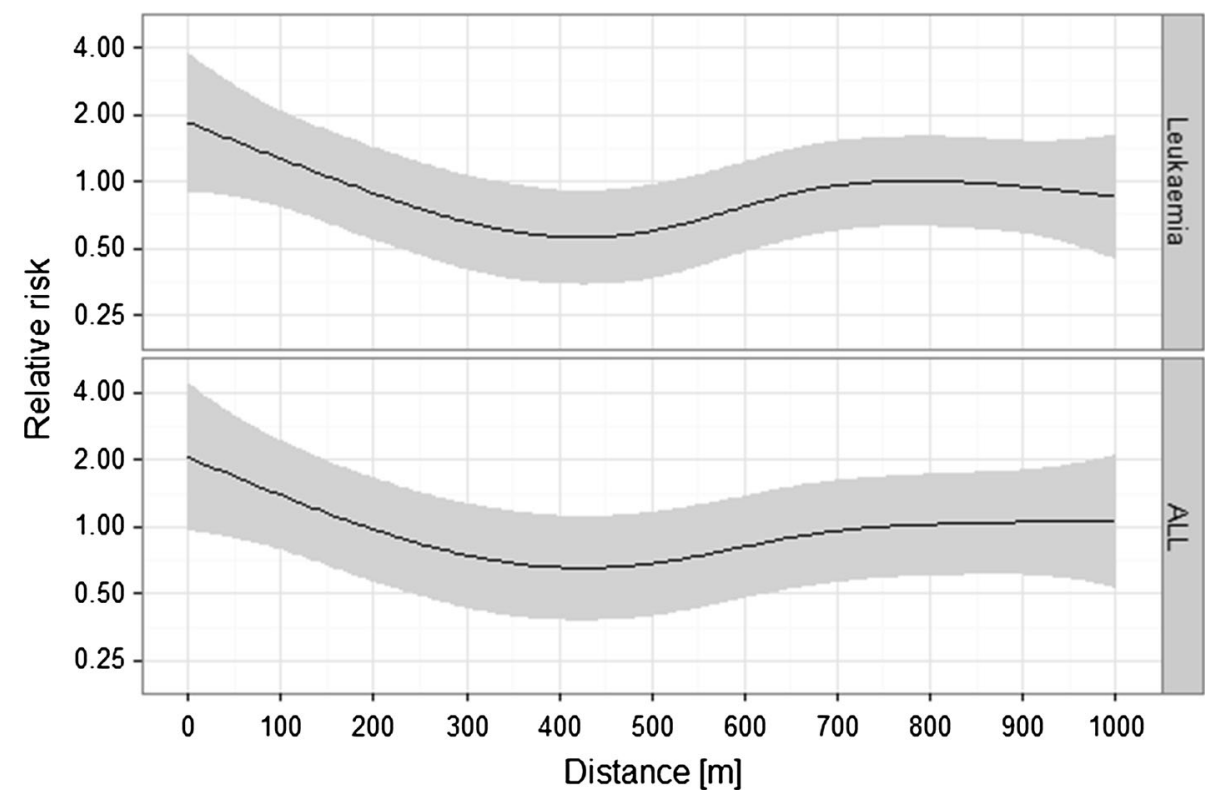

children with stable place of residence before entering the cohort. Vehicle exhaust contains known carcinogens and the risk increase observed in our study parallels the marked peaks in pollution concentrations within this distance from highways observed in other studies. Our study thus provides further support that traffic related pollution may increase the risk of leukaemia in young children.

\begin{abstract}
Acknowledgments The authors thank Dr. Christian Kreis for his assistance in calculating distance to highways and creating the map. This work was supported by the Swiss Federal Office of Public Health (Grants 08.001616, 10.002946, 12.008357), Swiss Cancer League (Grant 02224-03-2008), and Swiss Cancer Research (Grants 3049-082012, 3515-08-2014). BD Spycher was supported by a Swiss National Science Foundation fellowship (PZ00P3_147987). The work of the Swiss Childhood Cancer Registry is supported by the Swiss Paediatric Oncology Group (www.spog.ch), Schweizerische Konferenz der kantonalen Gesundheitsdirektorinnen und -direktoren (www.gdk-cds. ch), Swiss Cancer Research (www.krebsforschung.ch), Kinderkrebshilfe Schweiz (www.kinderkrebshilfe.ch), Ernst-Göhner Stiftung, Stiftung Domarena and National Institute of Cancer Epidemiology and Registration (www.nicer.ch).
\end{abstract}

\section{Compliance with ethical standards}

Conflict of interest The authors declare that they have no conflict of interest.

Ethical approval Approval of the study was granted through the general cancer registry permission of the Swiss Childhood Cancer Registry by the ethics committee of the canton of Bern.

\section{Appendix: Members of study groups}

The members of the Swiss Paediatric Oncology Group Scientific Committee: R. A. Ammann (Bern), R. Angst (Aarau), M. Ansari (Geneva), M. Beck Popovic (Lausanne), E.
Bergstraesser (Zurich), P. Brazzola (Bellinzona), J. Greiner (St. Gallen), M. Grotzer (Zurich), H. Hengartner (St. Gallen), T. Kuehne (Basel), K. Leibundgut (Bern), F. Niggli (Zurich), J. Rischewski (Lucerne), N. von der Weid (Basel).

The members of the Swiss National Cohort Study Group: M. Egger (Bern), M. Bopp (Zurich), M. Puhan (Zurich), A. Spoerri (Bern), M. Zwahlen (Bern), N. Künzli (Basel), F. Paccaud (Lausanne), M. Oris (Geneva).

\section{References}

1. HEI panel on the health effects of traffic-related air pollution. Traffic-related air pollution: a critical review of the literature on emissions, exposure, and health effects. Boston, MA (2010). Report no.: special report 17. http://pubs.healtheffects.org/view. php?id=334. Accessed 07 Aug 2015.

2. IARC. Diesel and gasoline engine exhausts and some nitroarenes, vol. 105. Lyon, France: International Agency for Research on Cancer (IARC); 2012. http://monographs.iarc.fr/ENG/Mono graphs/PDFs/index.php. Accessed 07 Aug 2015.

3. IARC. A review of human carcinogens. Part F: chemical agents and related occupations, vol. 100F. Lyon, France: International Agency for Research on Cancer (IARC); 2012. http://mono graphs.iarc.fr/ENG/Monographs/PDFs/index.php. Accessed 07 Aug 2015.

4. Zhou Y, Levy JI. Factors influencing the spatial extent of mobile source air pollution impacts: a meta-analysis. BMC Public Health. 2007;7:89.

5. Hagler GSW, Baldauf RW, Thoma ED, et al. Ultrafine particles near a major roadway in Raleigh, North Carolina: downwind attenuation and correlation with traffic-related pollutants. Atmos Environ. 2009;43:1229-34.

6. Entec. Development of a methodology to assess population exposed to high levels of noise and air pollution close to major transport infrastructure. Final report for the European Commission. London, UK: Entec UK Limited 2006. http://ec.europa.eu/ 
environment/air/transport/pdf/final_report_main.pdf. Accessed 07 Aug 2015.

7. Pyatt D, Hays S. A review of the potential association between childhood leukemia and benzene. Chem Biol Interact. 2010;184:151-64.

8. Raaschou-Nielsen O, Reynolds P. Air pollution and childhood cancer: a review of the epidemiological literature. Int $\mathrm{J}$ Cancer. 2006;118:2920-9.

9. Amigou A, Sermage-Faure C, Orsi L, et al. Road traffic and childhood leukemia: the ESCALE study (SFCE). Environ Health Perspect. 2011;119:566-72.

10. Vinceti M, Rothman KJ, Crespi CM, et al. Leukemia risk in children exposed to benzene and PM10 from vehicular traffic: a case-control study in an Italian population. Eur J Epidemiol. 2012;27:781-90.

11. Heck JE, Wu J, Lombardi C, et al. Childhood cancer and trafficrelated air pollution exposure in pregnancy and early life. Environ Health Perspect. 2013;121:1385-91.

12. Badaloni C, Ranucci A, Cesaroni G, et al. Air pollution and childhood leukaemia: a nationwide case-control study in Italy. Occup Environ Med. 2013;70:876-83.

13. Filippini T, Heck JE, Malagoli C, Giovane CD, Vinceti M. A review and meta-analysis of outdoor air pollution and risk of childhood leukemia. J Environ Sci Health C Environ Carcinog Ecotoxicol Rev. 2015;33:36-66.

14. Bopp M, Spoerri A, Zwahlen M, et al. Cohort Profile: the Swiss National Cohort - a longitudinal study of 6.8 million people. Int $\mathbf{J}$ Epidemiol. 2009;38:379-84.

15. Schindler M, Mitter V, Rueegg CS et al. Death certificate notations in the Swiss Childhood Cancer Registry: Validation of registration procedures and completeness. In: Towards a harmonised cancer information system in Europe. Ispra, Italy: European Network of Cancer Registries (ENCR); 2014. http:// www.encr.eu/images/docs/Conference_2014/ENCR_Book_of_ Abstracts_2014.pdf. Accessed 07 Aug 2015.

16. Steliarova-Foucher E, Stiller C, Lacour B, Kaatsch P. International classification of childhood cancer, third edition. Cancer. 2005; 103:1457-67.

17. ARE. Nationales Güterverkehrsmodell des UVEK. Basismodell 2005: Modellbeschrieb und Validierung. Bern, Switzerland: Federal Office for Spatial Development (ARE) 2010. http://www. are.admin.ch/themen/verkehr/00258/00520/index.html?lang=en. Accessed 07 Aug 2015.

18. Panczak R, Galobardes B, Voorpostel M, et al. A Swiss neighbourhood index of socioeconomic position: development and association with mortality. J Epidemiol Community Health. 2012;66:1129-36.

19. Hauri D, Spycher B, Huss A, et al. Domestic radon exposure and risk of childhood cancer: a prospective census-based cohort study. Environ Health Perspect. 2013;121:1239-44.

20. Spycher BD, Lupatsch JE, Zwahlen M, et al. Background ionizing radiation and the risk of childhood cancer: a census-based nationwide cohort study. Environ Health Perspect. 2015;123:622-8.

21. Hauri DD, Spycher B, Huss A, et al. Exposure to radio-frequency electromagnetic fields from broadcast transmitters and risk of childhood cancer: a census-based cohort study. Am J Epidemiol. 2014;179:843-51.

22. Spycher BD, Feller M, Zwahlen M, et al. Childhood cancer and nuclear power plants in Switzerland: a census-based cohort study. Int J Epidemiol. 2011;40:1247-60.

23. Wood SN. Generalized additive models - an introduction with R. Boca Raton: Chapman \& Hall/CRC, Taylor \& Francis Group; 2006.

24. Pearson RL, Wachtel H, Ebi KL. Distance-weighted traffic density in proximity to a home is a risk factor for leukemia and other childhood cancers. J Air Waste Manag Assoc. 2000;50:175-80.

25. Crosignani P, Tittarelli A, Borgini A, et al. Childhood leukemia and road traffic: a population-based case-control study. Int $\mathbf{J}$ Cancer. 2004;108:596-9.
26. Langholz B, Ebi KL, Thomas DC, Peters JM, London SJ. Traffic density and the risk of childhood leukemia in a Los Angeles case-control study. Ann Epidemiol. 2002;12:482-7.

27. Harrison RM, Leung PL, Somervaille L, Smith R, Gilman E. Analysis of incidence of childhood cancer in the West Midlands of the United Kingdom in relation to proximity to main roads and petrol stations. Occup Environ Med. 1999;56:774-80.

28. Savitz DA, Feingold L. Association of childhood cancer with residential traffic density. Scand J Work Environ Health. 1989;15:360-3.

29. Raaschou-Nielsen O, Hertel O, Thomsen BL, Olsen JH. Air pollution from traffic at the residence of children with cancer. Am J Epidemiol. 2001;153:433-43.

30. Reynolds P, Von Behren J, Gunier RB, Goldberg DE, Hertz A. Residential exposure to traffic in California and childhood cancer. Epidemiology. 2004;15:6-12.

31. Reynolds P, Von Behren J, Gunier RB, Goldberg DE, Hertz A, Smith D. Traffic patterns and childhood cancer incidence rates in California, United States. Cancer Cause Control. 2002;13:665-73.

32. Von Behren J, Reynolds P, Gunier RB, et al. Residential traffic density and childhood leukemia risk. Cancer Epidemiol Biomark Prev. 2008; 17:2298-301.

33. Weng HH, Tsai SS, Chen CC, Chiu HF, Wu TN, Yang CY. Childhood leukemia development and correlation with traffic air pollution in Taiwan using nitrogen dioxide as an air pollutant marker. J Toxicol Environ Health A. 2008;71:434-8.

34. Ghosh JK, Heck JE, Cockburn M, Su J, Jerrett M, Ritz B. Prenatal exposure to traffic-related air pollution and risk of early childhood cancers. Am J Epidemiol. 2013;178:1233-9.

35. Whitworth KW, Symanski E, Coker AL. Childhood lymphohematopoietic cancer incidence and hazardous air pollutants in southeast Texas, 1995-2004. Environ Health Perspect. 2008;116:1576-80.

36. Reynolds P, Von Behren J, Gunier RB, Goldberg DE, Hertz A, Smith DF. Childhood cancer incidence rates and hazardous air pollutants in California: an exploratory analysis. Environ Health Perspect. 2003;111:663-8.

37. Heck JE, Park AS, Qiu J, Cockburn M, Ritz B. Risk of leukemia in relation to exposure to ambient air toxics in pregnancy and early childhood. Int J Hyg Environ Health. 2014;217:662-8.

38. Venkatram A, Isakov V, Seila R, Baldauf R. Modeling the impacts of traffic emissions on air toxics concentrations near roadways. Atmos Environ. 2009;43:3191-9.

39. Baldauf R, Thoma E, Hays M, et al. Traffic and meteorological impacts on near-road air quality: summary of methods and trends from the Raleigh near-road study. J Air Waste Manag Assoc. 2008;58:865-78.

40. Bowker GE, Baldauf R, Isakov V, Khlystov A, Petersen W. The effects of roadside structures on the transport and dispersion of ultrafine particles from highways. Atmos Environ. 2007;41:8128-39.

41. Stemmler K, Bugmann S, Buchmann B, Reimann S, Staehelin J. Large decrease of VOC emissions of Switzerland's car fleet during the past decade: results from a highway tunnel study. Atmos Environ. 2005;39:1009-18.

42. FOEN. Pollutant emissions from road transport, 1990 to 2035. Updated in 2010. Bern, Switzerland: Federal Office for the Environment (FOEN) 2010. http://www.bafu.admin.ch/pub likationen/publikation/01565/index.html?lang=en. Accessed 07 Aug 2015.

43. Ross Z, Kheirbek I, Clougherty JE, et al. Noise, air pollutants and traffic: continuous measurement and correlation at a high-traffic location in New York City. Environ Res. 2011;111:1054-63.

44. Pascuan CG, Uran SL, Gonzalez-Murano MR, Wald MR, Guelman LR, Genaro AM. Immune alterations induced by chronic noise exposure: comparison with restraint stress in BALB/c and C57B1/6 mice. J Immunotoxicol. 2014;11:78-83.

45. Greaves M. Infection, immune responses and the aetiology of childhood leukaemia. Nat Rev Cancer. 2006;6:193-203. 